\title{
Associations between Exposure to Persistent Organic Pollutants in Childhood and Overweight up to 12 Years Later in a Low Exposed Danish Population
}

\author{
Jeanett L. Tang-Péronard a, b Tina K. Jensen ${ }^{a} \quad$ Helle R. Andersen ${ }^{a}$ \\ Mathias Ried-Larsen ${ }^{c} \quad$ Anders Grøntved ${ }^{c, d}$ Lars B. Andersen ${ }^{c, d}$ \\ Clara A.G. Timmermann ${ }^{a}$ Flemming Nielsen ${ }^{a}$ Berit L. Heitmann ${ }^{b}, \mathrm{e}, \mathrm{f}$ \\ a Department of Environmental Medicine, Institute of Public Health, University of Southern \\ Denmark, Odense, Denmark; ${ }^{b}$ Research Unit for Dietary Studies, The Parker Institute and \\ Institute of Preventive Medicine, Copenhagen University Hospitals, Frederiksberg, Denmark; \\ 'Department of Sports Science and Clinical Biomechanics, University of Southern Denmark, \\ Odense, Denmark; ${ }^{\mathrm{d} C e n t r e}$ for Research in Childhood Health, University of Southern

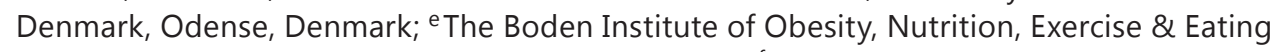 \\ Disorders, Sydney Medical School, Sydney, Australia; ${ }^{f}$ National Institute of Public Health, \\ University of Southern Denmark, Copenhagen, Denmark
}

\section{Key Words}

POPs · PCBs · Overweight · Obesity

\begin{abstract}
Background: Persistent organic pollutants (POPs) have metabolic disrupting abilities and are suggested to contribute to the obesity epidemic. We investigated whether serum concentrations of POPs at $8-10$ years of age were associated with subsequent development of overweight at age 14-16 and 20-22 years. Methods: The study was based on data from the European Youth Heart Study, Danish component (1997). Concentrations of several polychlorinated biphenyls (PCBs) and the organochlorine pesticides p,p-dichlorodiphenyldichloroethylene $(D D E)$ and hexachlorobenzene $(\mathrm{HCB})$ were measured in serum from children aged 8-10 years $(n=509)$. Information on BMI z-scores, waist circumference and \% body fat were collected at clinical examinations at ages 8-10, 14-16 and 20-22 years. Multiple linear regression analyses were performed taking potential confounders into account. Results: Overall, POP serum concentrations were low: median $\Sigma$ PCB $0.18 \mu \mathrm{g} / \mathrm{g}$ lipid, DDE $0.04 \mu \mathrm{g} / \mathrm{g}$ lipid and HCB $0.03 \mu \mathrm{g} / \mathrm{g}$ lipid. POPs were generally not associated with weight gain at $14-16$ and $20-22$ years of age, except for an inverse association among the highest exposed girls at 20-22 years of age, which might possibly be explained by multiple testing or residual confounding. Conclusion: This study suggests that, in a low exposed population, childhood serum concentrations of PCB, $\mathrm{DDE}$, and $\mathrm{HCB}$ are not associated with subsequent weight gain.


Tang-Péronard et al.: Associations between Exposure to Persistent Organic Pollutants in Childhood and Overweight up to 12 Years Later in a Low Exposed Danish Population

\section{Introduction}

While excess caloric consumption and a sedentary lifestyle in interaction with genetic heritage are well-recognized risk factors for obesity, the cause of the obesity epidemic remains unclear and evidence for effects of several 'non-traditional' putative environmental contributors is emerging [1,2]. A proposed alternative environmental risk factor is exposure to chemicals with endocrine disrupting abilities (EDCs) [3]. Persistent organic pollutants (POPs) include chemicals such as polychlorinated biphenyls (PCBs) and the organochlorine pesticides hexachlorobenzene (HCB) and p,p-dichlorodiphenyldichloroethylene (DDE) (major metabolite of DDT) - a part of a group of chemicals considered as EDCs and hypothesized to have obesogenic properties [4]. Because of their lipophilicity and long half-lives, they accumulate in the food chain, and the general population is still exposed to low doses of these substances [5] despite a ban (PCBs, HCB) or restriction (DDT) on the production and use since the 1970s by the Stockholm agreement [6]. Epidemiologic studies, have reported associations between PCBs, DDE, HCB and obesity [7-10] as well as other metabolic disorders such as insulin resistance, type 2 diabetes and metabolic syndrome [11-13]. However, there are few longitudinal studies of POP exposure and subsequent weight gain among children.

The association between exposure to POPs and body weight is proposed to be inversely U-shaped, and POPs thus potentially associated with weight gain at environmentally relevant low concentrations and weight loss or no association at higher concentrations $[9,14]$, which may explain the disparity of findings across studies. However, high- or low-dose ranges are not yet established $[14,15]$. We have previously reported an association between prenatal exposure to POPs (PCBs, DDE) and obesity [16] among moderately exposed girls with overweight mothers from the Faroese Islands examined at age 5 and 7 years. An inverse association between serum insulin and PCB exposure was recently observed in a low exposed population of Danish children aged 8-10 years of age [17], and we here examine, in the same cohort, whether exposure to POPs was associated with weight development at 6 and 12 years of follow-up.

\section{Material and Methods}

\section{Subjects and Sampling}

The data were derived from the Danish part of the European Youth Heart Study (EYHS). The subjects were recruited in 1997 through a two-stage cluster sampling from 25 different schools in the municipality of Odense and stratified according to location and socioeconomic character. They participated as 8- to 10-year-old 3rd grade children, in the follow-up study in 2003 as 14- to 16-year-old 9th grade adolescents, and in the second follow-up study in 2009 as 20- to 22-year-old young adults. The study design, sampling, and methods have been described in more detail elsewhere $[18,19] .590$ of 771 recruited 3rd grade children participated in EYHS-I; 509 had adequate amounts available for POP analyses. A total of 384 of these children were re-examined as 9 th grade students (14-16 years), and 309 children as 20- to 22-year-old adults, corresponding to $49.8 \%$ and $40.1 \%$ of the original sample frame, respectively. Puberty was furthermore assessed at the age of 12 years. The present report is based on the cohort members who were examined at 8-10 years of age and participated in follow-up examination(s) at 14-16 years and/or at 20-22 years of age and who provided information on the chemicals PCBs, DDE, HCB, and covariates. In total, overall clinical data were available for 278 children (123 boys) and 236 adults (106 men).

The Danish part of the European Youth Heart Study adhered to the Helsinki Declaration and was approved by the local ethics committee [19].

Anthropometric Measurements

All measurements were carried out using standardized methods, which have been described in detail elsewhere $[18,19]$. 
Tang-Péronard et al.: Associations between Exposure to Persistent Organic Pollutants

Height and weight were assessed by standard anthropometric procedures. Height was measured to the nearest $\mathrm{mm}$ using a stadiometer, and weight was measured to the nearest $100 \mathrm{~g}$ using a beam-scale-type weight [19]. BMI was calculated as weight (in kg) / (height ${ }^{2}$ (in $\mathrm{m}^{2}$ ) and converted to sex-specific BMI-for-age z-scores (child value minus mean value for sex and age divided by standard deviation for sex and age) using WHO standards (WHO, 2007). Waist circumference was measured twice with a metal anthropometric tape midway between the lower rib margin and the iliac crest. The mean value of the two measurements was used for analysis. Skinfold thickness (SFT) was measured at age 8-10 years, 14-16 years and 20-22 years using a Harpenden fat caliper (John Bull; British Indicators Ltd, Birmingham, UK) over the triceps brachii and biceps brachii muscles, subscapularly, and superior to the anterior superior iliac spine [20], and finally expressed as the sum of the four skinfold thicknesses ( $\Sigma \mathrm{SF}$ ). The calculation of \% body fat (\% BF) was estimated from the measurements of SFT using the equations given by Slaughter et al. [20].

\section{Measurement of Exposure}

PCBs, DDE, and HCB were analyzed from the enrolment blood samples (at age 8-10 years), by use of solid-phase extraction and sample concentration. Separation of the congeners and quantitation was performed by gas chromatography using a dual capillary column system with microelectron capture detection. The analyses were carried out at the Department of Environmental Medicine, University of Southern Denmark. The quality assurance of this analysis was verified by regular participation in international quality assurance programs [21]. The results were standardized by blood lipids [21] and reported as $\mu \mathrm{g} / \mathrm{g}$ lipid. The median limit of quantification was $0.06 \mathrm{ng} / \mathrm{ml}$ for PCBs, DDE, and HCB. The limit of detection (LOD) was $0.03 \mathrm{ng} / \mathrm{ml}$ which, at a mean lipid concentration of $6 \mathrm{~g} / \mathrm{l}$, corresponds to $0.005 \mu \mathrm{g} / \mathrm{g} \mathrm{lipid}$. Values under LOD were imputed to LOD/2 $=0.0025 \mu \mathrm{g} / \mathrm{g}$ lipid for two individuals [22]. The inter-batch repeatability ranged between 3 and 11\%, whereas the between-batch reproducibility ranged between 2 and 9\%. The accuracy reported as bias ranged between -15.0 and $8.3 \%$. To avoid problems with congeners not assessed and concentrations below the LOD, a simplified concentration of the sum of PCBs ( $\mathrm{PCB}$ ) was calculated as the sum of the three primary congeners with the longest half-lives (PCB138, PCB153, PCB180) multiplied by two [23], given that they make up approximately $50 \%$ of all PCB congener concentration in serum.

\section{Measurement of Covariates}

Information on the covariates breastfeeding, maternal educational level (socioeconomic status; SES), and maternal smoking was obtained through questionnaires at baseline. Follow-up questionnaires were used if information was missing from baseline. Maternal BMI was calculated from self-reported information on height and weight. Pubertal status was assessed by the investigators from a scale of pictures according to Tanner (1962) - girls according to breast development and pubic hair growth and boys according to genital development and pubic hair growth [24]. Physical fitness was determined by a maximal work test (wattmax test), performed as a progressive maximal cycle ergometer test (cycle ergometer Monark ergomedi 839; Monark Exercise AB, Vanobro, Sweden), and calculated as the maximal power output (wattmax). Dietary intake of the children at 8-10 years of age was assessed using a 24-hour recall face-to-face interview supported by a parent-assisted food record. The dietary information was computed (intake of total energy, total fat, monounsaturated fat, polyunsaturated fat, protein, carbohydrate, n-3 fatty acid, and n- 6 fatty acid) in a database, by which it was possible to calculate nutrient information on the individual food items or whole meals and diets via the Danish national food composition tables [25].

\section{Statistical Analysis}

$\Sigma$ PCB, DDE and HCB were divided into tertiles, and differences in characteristics of the population according to sex and tertiles of POPs were tested as appropriate by ANOVA or chi-square tests. Descriptive statistics were given as means and standard deviations or proportions. Exposure parameters were log-transformed to obtain normally distributed residuals with a homogeneous variance. Linear regression analyses were performed to examine the association between POP concentration at 8-10 years of age and BMI z-scores, waist circumference or \% BF at 14-16 and 20-22 years of age. Based on previous epidemiological findings, covariates at baseline and at 14-16 and 20-22 years were defined from a priori considerations of relevant factors that might influence the outcome variables and were excluded stepwise if they did not affect the beta estimates by more than 10\%. Accordingly, adjustment was made for SES (low/medium/high), breast-feeding status ( $<1 / \geq 1$ month), fitness (based on maximal power output (W) per kg (continuous)), maternal BMI (continuous), and maternal smoking (yes/no). Fitness was not adjusted for in the analyses of the 20- to 22-year-olds because of missing values $(n=112)$; however, it was included in a sensitivity analysis. 
Tang-Péronard et al:: Associations between Exposure to Persistent Organic Pollutants in Childhood and Overweight up to 12 Years Later in a Low Exposed Danish Population

Table 1. Child and maternal characteristics according to tertiles of $\Sigma$ PCB at 8-10 years of age. Mean, EYHS cohort

\begin{tabular}{|c|c|c|c|c|c|c|c|c|}
\hline \multirow[t]{3}{*}{ Population characteristics } & \multicolumn{8}{|c|}{ Tertiles of $\Sigma \mathrm{PCB}^{*}(\mu \mathrm{g} / \mathrm{g}$ lipid $)$} \\
\hline & \multicolumn{4}{|c|}{ girls $(n=214)$} & \multicolumn{4}{|c|}{ boys $(n=178)$} \\
\hline & $<0.16$ & $0.16-0.28$ & $>0.28$ & $\mathrm{p}$ value & $<0.14$ & $0.14-0.25$ & $>0.25$ & $\mathrm{p}$ value ${ }^{\dagger}$ \\
\hline \multicolumn{9}{|l|}{ BMI z-score } \\
\hline 8-10 years & $0.63(1.0)$ & $0.26(1.0)$ & $-0.24(0.8)$ & $<0.001$ & $0.89(1.1)$ & $0.17(0.9)$ & $-0.03(0.9)$ & $<0.001$ \\
\hline $14-16$ years & $0.58(1.0)$ & $0.11(0.7)$ & $-0.19(0.7)$ & $<0.001$ & $0.28(1.0)$ & $0.02(1.0)$ & $-0.09(0.8)$ & 0.16 \\
\hline $20-22$ years & $0.94(1.0)$ & $0.53(0.8)$ & $0.02(0.7)$ & $<0.001$ & $1.06(1.1)$ & $0.57(1.1)$ & $0.50(1.0)$ & 0.04 \\
\hline \multicolumn{9}{|l|}{ Waist circumference, $\mathrm{cm}$} \\
\hline $8-10$ years & $60.4(6.1)$ & $57.6(6.0)$ & $56.3(4.0)$ & $<0.001$ & $61.2(6.6)$ & $57.5(4.4)$ & $57.2(4.9)$ & 0.001 \\
\hline $14-16$ years & $76.5(8.9)$ & $71.8(5.7)$ & $71.1(4.9)$ & $<0.001$ & $77.4(10.0)$ & $75.3(8.0)$ & $73.6(4.8)$ & 0.07 \\
\hline 20-22 years & $79.0(9.8)$ & $74.8(7.9)$ & $74.3(7.1)$ & 0.01 & $87.2(13.5)$ & $85.2(11.5)$ & $81.0(9.5)$ & $<0.05$ \\
\hline \multicolumn{9}{|l|}{$\% \mathrm{BF}$} \\
\hline $8-10$ years & $22.0(6.9)$ & $19.7(6.9)$ & $15.6(4.7)$ & $<0.001$ & 20.7 (7.9) & $16.4(5.1)$ & $14.6(4.3)$ & $<0.001$ \\
\hline $14-16$ years & $28.1(6.2)$ & $24.3(4.9)$ & $22.9(3.8)$ & $<0.001$ & $19.8(9.0)$ & $18.4(8.4)$ & $15.8(4.6)$ & 0.04 \\
\hline 20-22 years & $33.2(10.2)$ & $29.8(8.0)$ & $29.2(7.2)$ & 0.05 & $30.5(15.1)$ & $27.6(11.7)$ & $24.3(8.2)$ & 0.06 \\
\hline Tanner $8-10$ years $(1-2 / 3), \%$ & $59 / 41$ & $70 / 30$ & $83 / 17$ & 0.01 & $100 / 0$ & $100 / 0$ & $100 / 0$ & NA \\
\hline Tanner 12 years $(1-2 / 3), \%$ & $31 / 69$ & $38 / 62$ & $42 / 58$ & 0.87 & $61 / 39$ & $67 / 33$ & $76 / 24$ & 0.23 \\
\hline Breastfed, \% & 83.3 & 91.2 & 97.1 & 0.02 & 74.1 & 81.4 & 100 & $<0.001$ \\
\hline SES (low/medium/high), \% & $24 / 54 / 22$ & $18 / 35 / 47$ & $8 / 32 / 60$ & $<0.001$ & $37 / 44 / 19$ & $26 / 42 / 32$ & $14 / 35 / 51$ & 0.004 \\
\hline Fitness, $\mathrm{W} / \mathrm{kg}$ & $2.6(0.6)$ & $2.9(0.5)$ & $3.1(0.4)$ & $<0.001$ & $3.1(0.5)$ & $3.3(0.5)$ & $3.5(0.4)$ & $<0.001$ \\
\hline Maternal BMI, kg/m² & $23.8(3.6)$ & $23.1(3.9)$ & $22.4(2.7)$ & 0.07 & $24.9(3.7)$ & $23.9(4.1)$ & $22.9(3.2)$ & 0.02 \\
\hline Maternal smoking, \% & 47.1 & 42.2 & 22.1 & 0.005 & 42.9 & 37.9 & 15.5 & 0.003 \\
\hline
\end{tabular}

PCBs = Polychlorinated biphenyl(s); SES = socioeconomic status (maternal educational level).

*PCB concentration in $\mu \mathrm{g} / \mathrm{g}$ lipid, measured in child serum at age 8-10 years (PCB concentration is based on sum of PCB congeners 138, 153 and 180).

${ }^{\dagger} \mathrm{P}$ values were determined by using ANOVA and Pearson's chi-square tests of differences across tertiles of $\Sigma$ PCB.

Obesity measures at baseline were considered as obligatory covariates and were furthermore included in all adjusted analyses, as was baseline BMI z-score in the analyses of waist circumference as an outcome. The covariates birth weight, start of puberty at 8-10 and 12 years (yes / no), maternal alcohol consumption during pregnancy (yes / no), and ethnicity (Danish / non-Danish) were not adjusted for, as they did not affect the beta estimate by more than $10 \%$. To examine dose-response relationships, POPs were divided into tertiles. Further, to assess whether sex interacted with the association between POPs and adiposity measures, a multiplicative term with the exposure variable was included in the analyses. Additionally, in sensitivity analyses, the same procedure was applied to assess possible effect modification from baseline BMI and daily intake of nutrients, ( $\mathrm{p}<0.1$ used to define significant interactions).

Statistical significance was assumed when $\mathrm{p}<0.05$ (two-sided). All analyses were performed using STATA software, version 12 (STATA Corp., College Station, TX, USA).

\section{Results}

A total of 278 (123 boys) were initially examined at 8-10 years of age and followed up at 14-16 years of age; 236 (106 boys) were examined at 8-10 years of age and followed up at 20-22 years of age; 207 (95 boys) participated in all 3 examinations (supplemental fig. 1 (supplemental material available at http://content.karger.com/ProdukteDB/produkte. asp?doi=438834)). Among girls, the median for $\Sigma$ PCB was $0.18 \mu \mathrm{g} / \mathrm{g}$ (range $0.04-1.11 \mu \mathrm{g} / \mathrm{g}$ ), for DDE $0.04 \mu \mathrm{g} / \mathrm{g}$ (range 0.01-0.72 $\mu \mathrm{g} / \mathrm{g}$ ), and for HCB $0.03 \mu \mathrm{g} / \mathrm{g}$ (range $0.01-0.10 \mu \mathrm{g} / \mathrm{g}$ ); among boys the respective values were $0.20 \mu \mathrm{g} / \mathrm{g}$ (range $0.02-1.15 \mu \mathrm{g} / \mathrm{g}$ ), $0.04 \mu \mathrm{g} / \mathrm{g}$ (range $0.01-0.72 \mu \mathrm{g} / \mathrm{g}$ ), $0.03 \mu \mathrm{g} / \mathrm{g}$ (range $0.00-0.21 \mu \mathrm{g} / \mathrm{g}$ ), respectively. 
Tang-Péronard et al.: Associations between Exposure to Persistent Organic Pollutants in Childhood and Overweight up to 12 Years Later in a Low Exposed Danish Population

The characteristics of the population according to tertiles of $\Sigma$ PCB and sex are shown in table 1. Compared to children from the lowest tertile, those from the highest tertile had significantly lower BMI, waist circumference and \% BF at 8-10, 14-16 and 20-22 years of age. Moreover, the frequency of breastfeeding was higher, they were from a higher social class, they had a better fitness score, their mothers had a lower BMI, and fewer of their mothers were smokers. In addition, compared to girls from the lowest tertile, fewer girls from the highest exposure tertile had started their puberty at 8-10 years of age. Results were essentially similar for DDE and HCB (data not shown).

Interactions were observed for sex that modified the associations between $\Sigma$ PCB or DDE and BMI at 20-22 years of age ( $p=0.05$ or $p=0.02$, respectively) as well as between $\Sigma$ PCB and waist circumference or body fat $\%$ BF at $14-16$ years of age $(p=0.04$ and $p=0.03$, respectively). The results of the multivariate analyses are therefore presented for girls and boys separately.

In the crude analyses between tertiles of $\Sigma \mathrm{PCB}$ at 8-10 years of age and the measurements of adiposity at 14-16 and 20-22 years of age, a lower BMI z-score, waist circumference and $\%$ BF was observed for those in the highest tertile of $\Sigma$ PCB (table 2). After adjustment for baseline obesity, breastfeeding, SES, fitness, maternal BMI and maternal smoking, the majority of the observed inverse associations were generally attenuated, but the inverse association between $\Sigma$ PCB and change in BMI persisted among those in the highest (mean $0.4 \mu \mathrm{g} / \mathrm{g}$ lipid) compared to the lowest exposure tertile (mean $0.1 \mu \mathrm{g} / \mathrm{g}$ lipid) among the 20- to 22-year-old women (BMI z-scores $-0.44 ; 95 \% \mathrm{CI}-0.80,-0.08 ; \mathrm{p}=0.02$ ). Similar findings were seen for the individual PCB congeners, DDE and HCB (supplemental tables 1, 2 (supplemental material available at $h t t p: / / c o n t e n t . k a r g e r . c o m / P r o d u k t e D B /$ produkte.asp?doi=438834)). Also, DDE was related to a change in \% BF and both DDE and HCB to a change in waist circumference. Further analyses including only those with complete information at all three surveys (207 individuals) gave essentially similar results (data not shown).

\section{Discussion}

We found no evidence for associations between $\Sigma$ PCB, DDE and HCB at age 8-10 years of age and subsequent 6- and 12-year development in overall or abdominal obesity. Before adjustment, a higher $\Sigma$ PCB, DDE, and HCB exposure at age 8-10 years of age was inversely associated with subsequent 6 - and 12-year change in BMI, change in waist circumference, and change in \% BF at both 14-16 and 20-22 years of age; however, after adjustment for relevant confounders, the majority of the associations were attenuated and no longer statistically significant, except for a change in BMI among 20- to 22-year-old women. Although some POPs display estrogenic effects that may explain the diverging findings among the two sexes, we regard the findings of inverse associations among the 20- to 22-year-old women as spurious and more likely explained by multiple testing or residual confounding. As such, we performed many analyses, and, according to a calculated Bonferroni-adjusted significance level ( $\mathrm{p} \leq$ 0.002 ), the inverse associations were no longer significant. Alternatively, it may be related to residual confounding. Indeed, we did not adjust for differences in fitness at age 20-22 years because of many missing values $(n=112)$, which may add to explain the inverse association. However, sensitivity analyses performed for those with measures of fitness gave essentially similar results, making residual confounding from fitness less likely. It may also be that a low exposure to POPs has a protective effect in regard to obesity development; however, considering the fact that EDCs target many different endpoints [26], this explanation seems unlikely. Finally, it could be argued that POPs may have a toxic effect leading to weight loss. However, the low exposure level in our population argues against this explanation. 
Tang-Péronard et al.: Associations between Exposure to Persistent Organic Pollutants in Childhood and Overweight up to 12 Years Later in a Low Exposed Danish Population

ษن

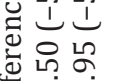

แั๊

กํํㄱ

○ं $\infty$

记

कृष

崩

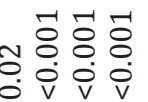

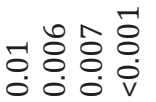

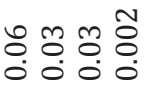

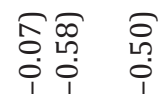

00

ช

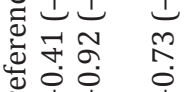
ग

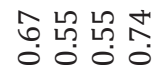

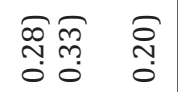

- $\overbrace{}^{\infty} \infty$

䚄 넌 눙ㅇํ

(1)

i

จิ่

$\stackrel{0}{0} \underbrace{i}_{\infty}$

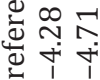

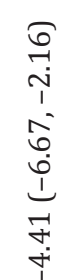

ิㅗㅇㅎㅀ

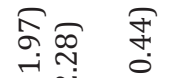

เก

\&

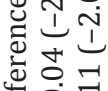

屯․

유

응용용

v

两F F



ㄱำ

व

论

¿

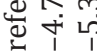

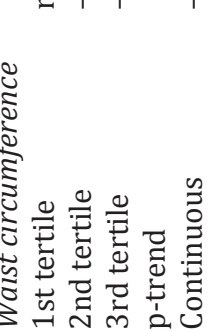

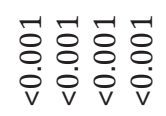

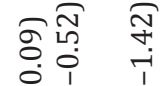

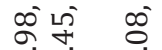

过茎

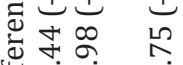

巡

$\begin{array}{cccc} & \mathbb{N} & m & 0 \\ 0 & 0 & 0 \\ 0 & 0 & 0 & 0 \\ 0\end{array}$

코음

ले เ्ञ

\&

एँّ

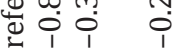

종 สু

î.

ळ

\&ํำ

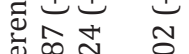

这袋 
Tang-Péronard et al.: Associations between Exposure to Persistent Organic Pollutants in Childhood and Overweight up to 12 Years Later in a Low Exposed Danish Population

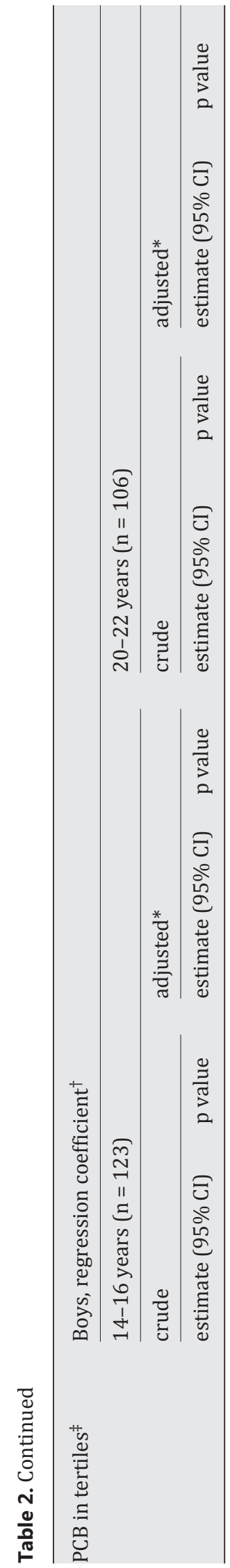

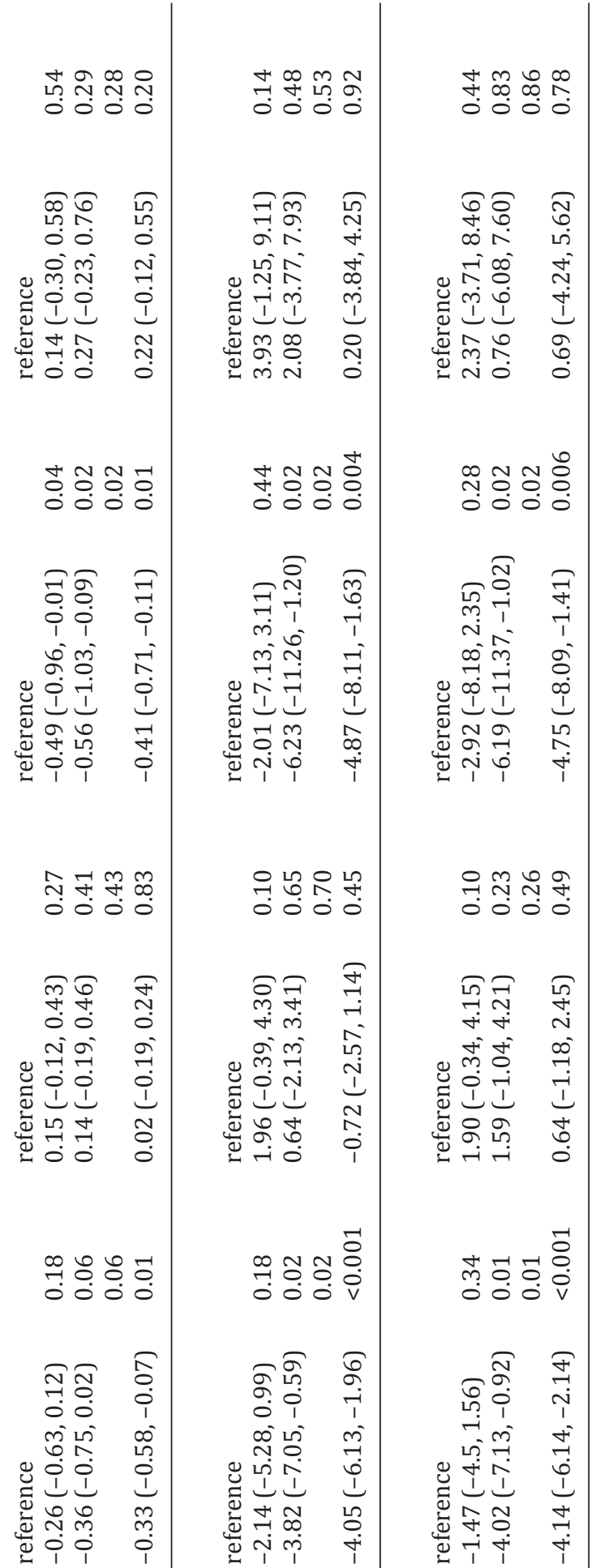

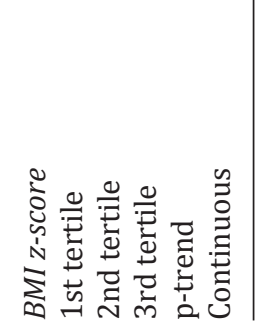

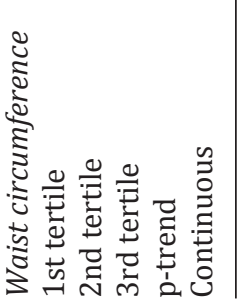

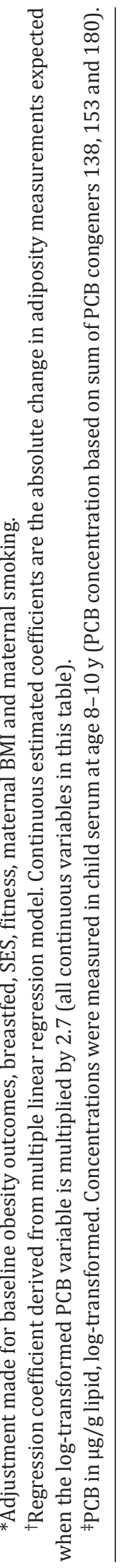


Tang-Péronard et al.: Associations between Exposure to Persistent Organic Pollutants in Childhood and Overweight up to 12 Years Later in a Low Exposed Danish Population

Our findings of no apparent obesogenic effect of POPs do not seem in agreement with the experimental evidence that generally has reported obesogenic effects of exposure to doses of POPs considered relevant to humans [27]. The human evidence, though, is more diverse and also difficult to compare because of methodological differences between studies. Indeed, findings tend to differ according to type of POPs investigated. The evidence for obesogenic effects from the organochlorine pesticide HCB is still limited, whereas DDE generally has been found to have obesogenic effects [9]. As such, a growing body of prospective epidemiological studies has shown an association between prenatal concentration of DDE and subsequent development of obesity [9]. Similar findings have been reported in prospective studies with exposures in adults [28, 29] and in several cross-sectional studies reviewed earlier [9]. However, the human evidence for an obesogenic effect of PCBs is less clear [27]. The contrasting findings may be explained by differences in the measured PCBs. Some studies only measured PCB153 as a marker of total PCB exposure, while others [9], like in the present study, investigated the effects of a sum of different PCBs, which is generally considered more relevant [23]. In addition, associations between POPs and obesity development may not be linear or monotonous. Indeed, we recently proposed that the relationship was inversely U-shaped [9], suggesting that associations would be direct at low exposures $(<1.0 \mu \mathrm{g} / \mathrm{g}$ lipid), but inverse or not existing at higher exposures $(>4.0 \mu \mathrm{g} / \mathrm{g}$ lipid).

The level of exposure in our population was low (median $\Sigma$ PCB $0.19 \mu \mathrm{g} / \mathrm{g}$ lipid) and thus contradicting the hypothesis of exposure related obesogenic effects at low exposures. Compared to the study of Hertz-Picciotto et al. [30], the exposure level in the present study was lower (median $\Sigma$ PCB $0.62 \mu \mathrm{g} / \mathrm{g}$ lipid) and slightly higher than the exposure level in Verhulst et al. [10] (median $\Sigma$ PCB $0.10 \mu \mathrm{g} / \mathrm{g}$ lipid) who both found direct associations between prenatal exposure to $\Sigma \mathrm{PCB}$ and weight gain among children. However, both studies concerned prenatal exposure to $\Sigma \mathrm{PCB}$. Because EDCs potentially have the largest impact when exposure occurs during fetal development [31], time of measurement of POPs in our cohort may attribute to the observed absence of obesogenic effects. On the other hand, other studies have found that POPs measured at age 8-10 years reflects both the pre- and postnatal exposure, and may be a good indicator also for prenatal POP exposure because of their long half-lives [32]. However, if POPs are measured after obesity onset, it may well be that the concentration of POPs has been diluted because of increased adipose tissue, and a bias may occur [27]. Serum POPs may be lower in those with a larger body mass because of a greater volume of distribution and sequestration in adipose tissue [33]. A dilution effect would result in a reverse causation phenomenon where our findings of lower adiposity measurements among the highest exposed women then would be the attributable factor to higher concentration of POPs. A further stratification by baseline BMI (8-10 years of age) as a sensitivity analysis, revealed that the inverse associations were present among the normal-weight women only, which most likely was a result of the regression towards the mean phenomenon (data not shown) [34].

Recent cross-sectional findings performed in our cohort showed inverse associations between $\Sigma$ PCB and insulin, HOMA-IR or HOMA-B at 8-10 years of age [17], which was suggested to be related to a possible damage of the beta cells [35]. Hence, it may be speculated that the low PCB concentrations in the present study were too low to influence development of obesity, but may potentially be sufficient to contribute to metabolic disturbances, eventually leading to type 2 diabetes [36].

It may be speculated that belonging to a higher social class is associated with better lifestyle, but also with a concomitant higher POP exposure. As such, fish is the most significant source of exposure to POPs [37] and is more frequently consumed in higher social classes [38]. This may explain why the inverse associations between POPs and development in adiposity generally disappeared after adjustment for social class and related covariates. 
Tang-Péronard et al.: Associations between Exposure to Persistent Organic Pollutants

Furthermore, the social gradient in diet is not as strong among men than among women [39], which may explain the apparent and persisting gender difference for those aged 20-22 years. Because children from parents of higher social class had higher levels of POPs compared with children from those of lower social class, and because adiposity levels are lower among children from high social class parents, residual confounding from social class or other unmeasured variables cannot be excluded.

Finally, humans are not exposed to one single chemical only, but to a combination of several compounds of which some are not measured. As such, observed effects may be attributable to other chemicals than those measured, or a combination of the compounds may be the responsible factor here [40]. Hence, it may be speculated that the explanation for the observed obesogenic effects of POPs in the study of Verhulst et al. [10], with a similar level of exposure as the present study, may be attributable to some unmeasured chemicals with obesogenic properties.

Because POPs may increase the susceptibility to the effects of e.g. a high-fat diet [41], we investigated in sensitivity analyses whether a daily high intake of nutrients (intake of total energy, total fat, monounsaturated fat, polyunsaturated fat, protein, carbohydrate, n-3 fatty acid and n- 6 fatty acid) either modified or confounded the association between POPs and future weight gain, but did not observe any effect modification or confounding (data not shown).

The major strength of this study is the longitudinal design with a long follow-up that enabled us to examine association between POPs at 8-10 years of age and development of obesity at 14-16 or 20-22 years of age. Moreover, the prospective design also reduces the risk of reverse causation as seen in many of the cross-sectional studies. A limitation of our study is the timing of measure of POPs in our cohort that was done at 8-10 years of age. As such, we did not have any exact measure of the prenatal exposure and may therefore have missed the critical window for POP effects on obesity. A further limitation of our study is the modest sample size, which means that modest effects may have been missed. It should be noted that part of the covariates were assessed by questionnaires and self-report, which may have introduced bias. However, as participants were unaware of their PCB levels as well as their future obesity status, we do not expect differential misclassification bias due to residual confounding, although this cannot be ruled out.

In conclusion, we found no evidence for an obesogenic effect of $\Sigma$ PCB, DDE, HCB in a population of 8- to 10-year-old children with a low exposure to POPs and a follow-up time of 6-12 years. However, we did not measure POPs at the most sensitive window, e.g. prenatally, but at 9 years of age. Therefore, more studies are warranted to examine long-term potential obesogenic effects of both low and high exposures to POPs.

\section{Acknowledgements}

We thank all of the participants of the European Youth Heart Study and their families for their participation and the staff from The Institute of Sports Science and Clinical Biomechanics and Department of Environmental Medicine for their dedicated effort. The authors thank the participants and their families for their dedication to the project.

\section{Financial Support}

This work was supported by the Danish Council for Strategic Research, Program Commission on Health, Food and Welfare (grant 95-103-21990). 
Tang-Péronard et al.: Associations between Exposure to Persistent Organic Pollutants in Childhood and Overweight up to 12 Years Later in a Low Exposed Danish Population

\section{Authorship}

The authors' responsibilities were as follows - AG and MRL were responsible for the data collection; FN was in charge of the POP analyses; JLTP, TKJ, HRA and BLH were involved in the design of the current study; JLTP analyzed data and wrote the first draft of the manuscript; AGT and LBA provided assistance with data analysis; TKJ, HRA and BLH: supervised the work; and all authors were involved in data interpretation, revising the manuscript, and approved the final version of the manuscript.

\section{Disclosure Statement}

None of the authors had a conflict of interest.

\section{References}

1 Keith SW, Redden DT, Katzmarzyk PT, Boggiano MM, Hanlon EC, Benca RM, Ruden D, Pietrobelli A, Barger JL, Fontaine KR, Wang C, Aronne LJ, Wright SM, Baskin M, Dhurandhar NV, Lijoi MC, Grilo CM, DeLuca M, Westfall AO, Allison DB: Putative contributors to the secular increase in obesity: Exploring the roads less traveled. Int J Obes (Lond) 2006;30:1585-1594.

-2 McAllister EJ, Dhurandhar NV, Keith SW, Aronne LJ, Barger J, Baskin M, Benca RM, Biggio J, Boggiano MM, Eisenmann JC, Elobeid M, Fontaine KR, Gluckman P, Hanlon EC, Katzmarzyk P, Pietrobelli A, Redden DT, Ruden DM, Wang C, Waterland RA, Wright SM, Allison DB: Ten putative contributors to the obesity epidemic. Crit Rev Food Sci Nutr 2009;49:868-913.

3 Casals-Casas C, Desvergne B: Endocrine disruptors: from endocrine to metabolic disruption. Annu Rev Physiol 2011;73:135-162.

-4 Grün F, Blumberg B: Perturbed nuclear receptor signaling by environmental obesogens as emerging factors in the obesity crisis. Rev Endocr Metab Disord 2007;8:161-171.

5 Pelletier C, Imbeault P, Tremblay A: Energy balance and pollution by organochlorines and polychlorinated biphenyls. Obes Rev 2003;4:17-24.

6 Stockholm Convention on Persistent Organic Pollutants (POPs). DDT Register. 2009. http://chm.pops.int/ Implementation/Exemptions/AcceptablePurposesDDT/tabid/456/Default.aspx (last accessed July 21, 2015).

7 Mendez MA, Garcia R, Guxens M, Vrijheid M, Kogevinas M, Goni F, Fochs S, Sunyer J: Prenatal organochlorine compound exposure, rapid weight gain and overweight in infancy. Environ Health Perspect 2011;119:272278.

-8 Smink A, Ribas-Fito N, Garcia R, Torrent M, Mendez MA, Grimalt JO, Sunyer J: Exposure to hexachlorobenzene during pregnancy increases the risk of overweight in children aged 6 years. Acta Paediatr 2008;97:14651469.

-9 Tang-Péronard JL, Andersen HR, Jensen TK, Heitmann BL: Endocrine-disrupting chemicals and obesity development in humans: a review. Obes Res 2011;12:622-636.

-10 Verhulst SL, Nelen V, Den Hond E, Koppen G, Beunckens C, Vael C, Schoeters G, Desager K: Intra-uterine exposure to environmental pollutants and body mass index during the first three years of life. Environ Health Perspect 2009;117:122-126.

11 Codru N, Shymura MJ, Negoita S, Rej R, Carpenter DO: Diabetes in relation to serum levels of polychlorinated biphenyls and chlorinated pesticides in adult native Americans. Environ Res 2007;103:413-418.

$\$ 12$ Lee DH, Steffes MW, Sjodin A, Jones RS, Needham LL, Jacobs DR Jr: Low dose of some persistent organic pollutants predicts type 2 diabetes: a nested case-control study. Environ Health Perspect 2010;118:12351242.

13 Uemura H, Arisawa K, Hiyoshi M, Kitayama A, Takami H, Sawachika F, Dakeshita S, Nii K, Satoh H, Sumiyoshi Y, Morinaga K, Kodama K, Suzuki T, Nagai M, Suzuki T: Prevalence of metabolic syndrome associated with body burden levels of dioxin and related compounds among Japan's general population. Environ Health Perspect 2009;117:568-573.

14 Vandenberg LN, Colborn T, Hayes TB, Heindel JJ, Jacobs DR Jr, Lee DH, Shioda T, Soto AM, vom Saal FS, Welshons WV, Zoeller RT, Myers JP: Hormones and endocrine-disrupting chemicals: low-dose effects and nonmonotonic dose responses. Endocr Rev 2012;33:378-455.

15 Welshons WV, Thayer KA, Judy BM, Taylor JA, Curran EM, vom Saal FS: Large effects from small exposures. I. Mechanisms for endocrine-disrupting chemicals with estrogenic activity. Environ Health Perspect 2003;111: 994-1006.

-16 Tang-Péronard JL, Heitmann BL, Andersen HR, Steuerwald U, Grandjean P, Weihe P, Jensen TK: Association between prenatal polychlorinated biphenyl exposure and obesity development at ages 5 and $7 \mathrm{y}$ : a prospective cohort study of 656 children from the Faroe islands. Am J Clin Nutr 2014;99:5-13. 
Tang-Péronard et al:: Associations between Exposure to Persistent Organic Pollutants in Childhood and Overweight up to 12 Years Later in a Low Exposed Danish Population

17 Jensen TK, Timmermann AG, Rossing LI, Ried-Larsen M, Grontved A, Andersen LB, Dalgaard C, Hansen OH, Scheike T, Nielsen F, Grandjean P: Polychlorinated biphenyl exposure and glucose metabolism in Danish children aged 9 years. J Clin Endocrinol Metab 2014;99:E2643-2651..

18 Riddoch CJ, Edwards D, Page A, Froberg K, Andersen SA, Wedderkopp N, Brage S, Cooper AR, Sardinha LB, Harro M, Klasson-Heggebø L, van Mechelen W, Boreham C, Ekelund U, Andersen LB: The European Youth Heart Study - cardiovascular disease risk factors in children: rationale, aims, study design, and validation of methods. J Phys Activ Health 2005;2:115-129.

19 Wedderkopp N: Atherosclerotic Cardiovascular Risk Factors in Danish children and Adolescents. A Community Based Approach with a Special Reference to Physical Fitness and Obesity. Institute of Sport Science and Clinical Biomechanics, Faculty of Health Sciences, University of Southern Denmark, 2001.

20 Slaughter MH, Lohman TG, Boileau RA, Horswill CA, Stillman RJ, Van Loan MD, Bemben DA: Skinfold equations for estimation of body fatness in children and youth. Hum Biol 1988;60:709-723.

-21 Phillips DL, Pirkle JL, Burse VW, Bernert JT Jr, Henderson LO, Needham LL: Chlorinated hydrocarbon levels in human serum: effects of fasting and feeding. Arch Environ Contam Toxicol 1989;18:495-500.

22 Lubin JH, Colt JS, Camann D, Davis S, Cerhan JR, Severson RK, Bernstein L, Hartge P: Epidemiologic evaluation of measurement data in the presence of detection limits. Environ Health Perspect 2004;112:1691-1696.

23 Grandjean P, Weihe P, Needham LL, Burse VW, Patterson DGJ, Sampson EJ, Jørgensen PJ, Vahter M: Relation of a seafood diet to mercury, selenium, arsenic, and polychlorinated biphenyl and other organochlorine concentrations in human milk. Environ Res 1995;71:29-38.

24 Tanner JM: Growth and maturation during adolescence. Nutr Rev 1981;39:43-55.

25 Møller A, Saxholt E: The Composition of Foods, 4th ed (in Danish). Mørkhøj, Levnedsmiddelstyrelsen (The National Food Agency), 1996.

26 Vandenberg LN, Colborn T, Hayes TB, Heindel JJ, Jacobs DR Jr, Lee DH, Myers JP, Shioda T, Soto AM, vom Saal FS, Welshons WV, Zoeller RT: Regulatory decisions on endocrine disrupting chemicals should be based on the principles of endocrinology. Reprod Toxicol 2013;38:1-15.

27 Lee DH, Porta M, Jacobs DR Jr, Vandenberg LN: Chlorinated persistent organic pollutants, obesity, and type 2 diabetes. Endocr Rev 2014;35:557-601.

28 Lee DH, Lind L, Jacobs DR Jr, Salihovic S, van Bavel B, Lind PM: Associations of persistent organic pollutants with abdominal obesity in the elderly: the prospective investigation of the vasculature in Uppsala seniors (PIVUS) study. Environ Int 2012;40:170-178.

29 Lee DH, Steffes MW, Sjodin A, Jones RS, Needham LL, Jacobs DR Jr: Low dose organochlorine pesticides and polychlorinated biphenyls predict obesity, dyslipidemia, and insulin resistance among people free of diabetes. PLoS One 2011;6:e15977.

-30 Hertz-Picciotto I, Charles MJ, James RA, Keller JA, Willman E, Teplin S: In utero polychlorinated biphenyl exposures in relation to fetal and early childhood growth. Epidemiology 2005;16:648-656.

31 Bern HA: The fragile fetus; in Colborn T, Clement C (eds): Chemically-Induced Alterations in Sexual and Functional Development: The Wildlife/Human Connection. Princeton, Princeton Scientific Publishing, 1992, vol 21, pp 9-15.

32 Patandin S, Dagnelie PC, Mulder PG, Op de Coul E, van der Veen JE, Weisglas-Kuperus N, Sauer PJ: Dietary exposure to polychlorinated biphenyls and dioxins from infancy until adulthood: a comparison between breast-feeding, toddler, and long-term exposure. Environ Health Perspect 1999;107:45-51.

-33 Wolff MS, Anderson HA, Britton JA, Rothman N: Pharmacokinetic variability and modern epidemiology - the example of dichlorodiphenyltrichloroethane, body mass index, and birth cohort. Cancer Epidemiol Biomarkers Prev 2007;16:1925-1930. Bland JM, Altman DG: Regression towards the mean. BMJ 1994;308:1499.

-35 Jorgensen ME, Borch-Johnsen K, Bjerregaard P: A cross-sectional study of the association between persistent organic pollutants and glucose intolerance among Greenland Inuit. Diabetologia 2008;51:1416-1422.

-36 Hectors TL, Vanparys C, van der Ven K, Martens GA, Jorens PG, Van Gaal LF, Covaci A, De Coen W, Blust R: Environmental pollutants and type 2 diabetes: A review of mechanisms that can disrupt beta cell function. Diabetologia 2011;54:1273-1290.

-37 Darnerud PO, Atuma S, Aune M, Bjerselius R, Glynn A, Grawe KP, Becker W: Dietary intake estimations of organohalogen contaminants (dioxins, PCB, PBDE and chlorinated pesticides, e.G. DDT) based on Swedish market basket data. Food Chem Toxicol 2006;44:1597-1606.

38 Darmon N, Drewnowski A: Does social class predict diet quality? Am J Clin Nutr 2008;87:1107-1117.

39 McLaren L: Socioeconomic status and obesity. Epidemiol Rev 2007;29:29-48.

K0 Kortenkamp A: Ten years of mixing cocktails. Environ Health Perspect 2007;115:98-105.

-41 Grün F, Blumberg B: Environmental obesogens: Organotins and endocrine disruption via nuclear receptor signaling. Endocrinology 2006;147:50-55. 